\title{
$\mathrm{DAC}$ 를 이용한 Offset-PLL 설계 및 제작
}

\section{Design and Fabrication of a Offset-PLL with DAC}

\author{
임 주 현 · 송 성 찬 \\ Ju-Hyun Lim $\cdot$ Sung-Chan Song \\ 요 약
}

본 논문은 GSM(Global System for Mobile communications)에서 주로 사용되는 Offset-PLL(Phase Locked Loop) 방식을 사용하여 낮은 위상 잡음과 빠른 위상 고정 시간, 우수한 불요파 특성을 갖는 주파수 합성기를 설계 제작 하였다. 제안된 주파수 합성기의 구조는 3 번의 주파수 하향 변환을 통해 낮은 위상 잡음 갖도록 하였으며, 높은 주파수 해상도를 갖도록 세 개의 offset 주파수중 최종 offset 주파수를 DDS(Direct Digital Synthesizer)를 이용하여 생성하였다. 또한, 빠른 스위칭 속도를 가질 수 있도록 DAC(Digital to Analog Converter)를 사용하였다. DAC 사 용에 따른 위상 잡음 열화를 줄이기 위해 $\mathrm{DAC}$ 노이즈 제거를 위한 필터를 설계하여 성능을 개선하였다.

\section{Abstract}

In this paper, we designed a frequency synthesizer with a low phase noise and fast lock time and excellent spurious characteristics using the offset-PLL(Phase Locked Loop) that is used in GSM(Global System for Mobile communications). The proposed frequency synthesizer has low phase noise using three times down conversion and third offset frequency of this synthesizer is created by DDS(Direct Digital Synthesizer) to have high frequency resolution. Also, this synthesizer has fast switching speed using DAC(Digital to Analog Converter). but phase noise degraded due to DAC. we improved performance using the DAC noise filter.

Key words : Offset-PLL, DDS, DAC, Frequency Synthesizer, Lock Time

\section{I. 서 론}

통신 시스템 및 레이더 시스템 등에서 고주파 신 호원으로 사용되는 주파수 합성기 설계 방법으로 직 접 아날로그 주파수 합성 방식(DA)과 직접 디지털 주파수 합성 방식(DDS) 그리고 간접 아날로그 주파 수 합성 방식(PLL)으로 나뉘고 있다. 이렇게 만들어 지는 주파수 합성기의 주요 규격은 주파수 대역폭, 주파수 해상도, 위상 잡음, 위상 고정 시간, 불요파 특성이 있다. 특히, 레이더 시스템에서 사용되는 주 파수 합성기의 규격은 다른 어떤 시스템들보다 높
은 편이다. 본 논문은 레이더 시스템에서 사용되는 주파수 합성기를 제작하기 위해 간접 아날로그 주파 수 합성 방식의 하나로 $\mathrm{GSM}$ 에서 사용되고 있는 offset-PLL(Phase Locked Loop) 방식과 직접 디지털 주파수 합성 방식을 결합하여 낮은 위상 잡음, 높은 주파수 해상도, 빠른 스위칭 속도 및 우수한 불요파 특성을 갖는 $\mathrm{DAC}$ 를 이용한 offset-PLL을 설계 및 제 작하였다.

\section{II. 본 론}

\section{2-1 Offset-PLL}

「이 연구는 삼성탈레스 연구비의 지원으로 연구되었음.」

삼성탈레스(Samsung Thales Co., Ltd.)

·논 문 번 호 : 20101126-08S

·교 신 저 자 : 임주현(e-mail : atheion.lim@samsung.com)

· 수정완료일자 : 2011년 1월 25일 


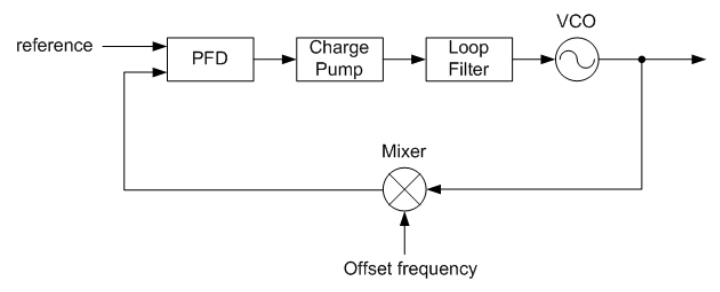

그림 1. Offset-PLL 블록 다이어그램

Fig. 1. Offset-PLL block diagram.

그림 1은 일반적인 offset-PLL의 블록 다이어그램 이다. 위 offset-PLL 방식은 일반적인 아날로그 PLL 와 달리 기준 주파수와 비교 주파수를 생성하기 위 해 주파수 분주기 대신 믹서를 사용한다. 믹서를 통 한 주파수 하향 변환을 통해 비교주파수를 생성해 냄으로써 일반적인 PLL방식보다 상대적으로 낮은 위상 잡음을 가질 수 있다는 장점을 갖는다 ${ }^{[1],[2]}$. 반 면, 믹서의 비선형성 때문에 불요파가 발생하게 되 는데 비교 주파수에 인접해 발생한 불요파는 제거하 기가 어려워 최종 합성된 주파수의 불요파 특성에 영향을 미친다 ${ }^{[3]}$. 또한, offset-PLL이 주파수 도약을 하기 위해서는 offset 주파수를 변환해야 하는데, 보 통은 offset 주파수원으로 또 다른 PLL 구조가 들어 가기도 한다.

\section{2-2 제안된 Offset-PLL}

그림 2는 기존의 offset-PLL의 성능을 개선하여 레 이더용 주파수 합성기로 사용하고자 제안된 offsetPLL의 블록 다이어그램이다. 본 논문에서 제안된 offset-PLL의 구성을 살펴보면 기본적으로 낮은 위상 잡음을 갖기 위해 3 개의 offset 주파수를 이용하였 으며, 3 개의 offset 주파수원은 고조파 발생기를 통 해서 생성하였다. 우선 fDDS 주파수는 DDS(Direct

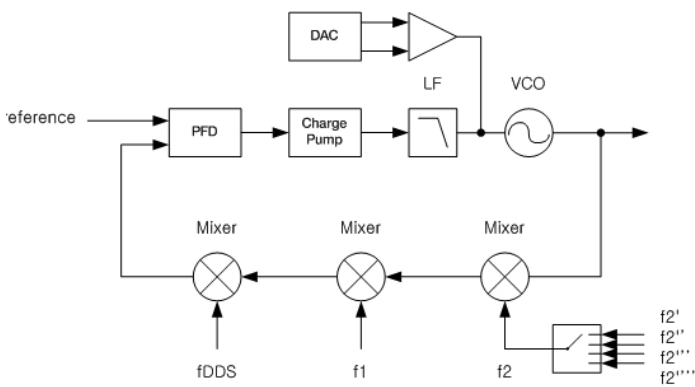

그림 2. 제안된 offset-PLL 블록 다이어그램

Fig. 2. Proposed offset-PLL block diagram. rect Digital Synthesizer)를 사용하여 발생시키며, DDS 의 클럭 주파수는 기준 신호의 8 번째 고조파를 사용 하였다. DDS를 사용한 이유는 제안된 주파수 합성 기가 주파수 고해상도를 가질 수 있도록 하기 위함 이다. 다음으로 $f_{1}$ 은 3 번째 고조파이며, $f_{2}$ 주파수는 25 번째, 26번째, 27번째, 28번째 고조파를 이용하여 최종 스위치에 의해서 선택되도록 하였다. $f_{2}$ 주파수 를 스위칭하는 이유는 Nyquist rate에 의해서 제한되 는 $\mathrm{DDS}$ 의 동작 영역의 제약을 극복하고자 주파수 도약시 서로 다른 4 개의 $f_{2}$ 주파수를 스위칭함으로 써 $500 \mathrm{MHz}$ 의 광대역 특성을 갖도록 하였다 ${ }^{[4]}$. 마지 막으로 주파수 합성기의 루프 필터의 조정 전압 출 력에 $\mathrm{DAC}$ 를 이용한 coarse tuning 전압을 연결하여 빠른 위상 고정 시간 및 스위칭 속도를 갖도록 설계 되었다.

\section{2-3 위상 등가 모델}

우선 설계에 앞서 제안된 주파수 합성기의 위상 잡음을 계산하기 위해서 표 1에 나타나는 설계 파라 미터를 가지고 그림 3 과 같이 위상 등가 모델을 꾸 며서 그 값을 계산하였다.

그림 3은 제안된 주파수 합성기의 위상 잡음 등가 모델로서 피드백 루프상의 출력 위상 잡음은 아래 식 (1)과 같이 표현할 수 있다 ${ }^{[5],[6]}$.

$$
\begin{aligned}
\theta_{0}= & \frac{K_{d} \cdot L(s) \cdot \frac{K_{0}}{s}}{1+K_{d} \cdot L(s) \cdot \frac{K_{0}}{s}} \cdot\left(\theta_{r}+\theta_{f 1}+\theta_{f 2}+\theta_{D D S}\right) \\
& +\frac{1}{1+K_{d} \cdot L(s) \cdot \frac{K_{0}}{s}} \cdot\left(\theta_{V}+\theta_{D A C} \cdot \frac{K_{0}}{s}\right)
\end{aligned}
$$

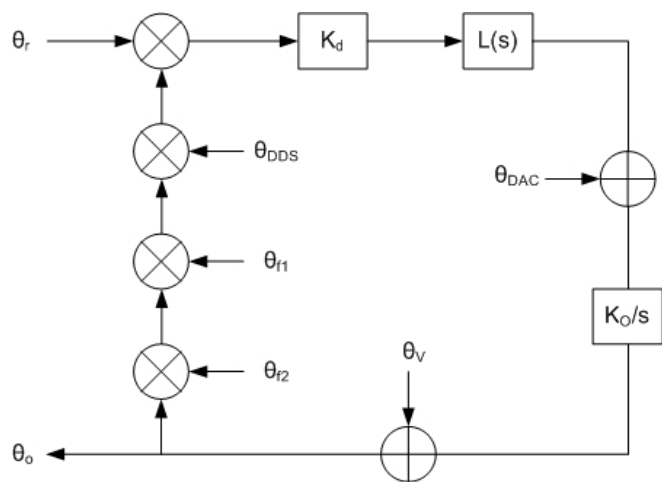

그림 3. 제안된 offset-PLL 위상 등가 모델

Fig. 3. Proposed offset-PLL phase equivalent model. 
표 1. 제안된 offset-PLL 설계 파라미터

Table 1. Proposed offset-PLL design parameter.

\begin{tabular}{|l|c|}
\hline Charge pump gain & $K_{d}$ \\
\hline Loop filter transfer function & $L(s)$ \\
\hline VCO voltage gain & $K_{0}$ \\
\hline Reference 위상 & $\theta_{r}$ \\
\hline$f_{1}$ 위상 & $\theta_{f 1}$ \\
\hline$f_{2}$ 위상 & $\theta_{f 2}$ \\
\hline DDS 위상 & $\theta_{D D S}$ \\
\hline DAC 위상 & $\theta_{D A C}$ \\
\hline VCO 위상 & $\theta_{V}$ \\
\hline 출력 위상 & $\theta_{0}$ \\
\hline
\end{tabular}

식 (1)은 아래와 같이 간략히 표현할 수 있다.

$$
\begin{aligned}
\theta_{0}= & H(s) \cdot\left(\theta_{r}+\theta_{f 1}+\theta_{f 2}+\theta_{D D S}\right) \\
& +(1-H(s)) \cdot\left(\theta_{V}+\theta_{D A C} \cdot \frac{K_{0}}{s}\right)
\end{aligned}
$$

여기서 $H(s)=\frac{K_{d} \cdot L(s) \cdot T_{0}}{s+K_{d} \cdot L(s) \cdot T_{0}}$ 이다.

이렇게 계산된 위상 잡음 방정식은 아래와 같이 PSD(Power Spectral Density)로 표현함으로써 offset$\mathrm{PLL}$ 의 최종 출력 위상 잡음을 계산할 수 있다.

$$
\begin{aligned}
S_{\phi}(\omega)= & |H(\omega)|^{2} \cdot\left(\Phi_{r}(\omega)+\Phi_{f 1}(\omega)+\Phi_{f 2}(\omega)+\Phi_{D D S}(\omega)\right) \\
& +|1-H(\omega)|^{2} \cdot\left(\Phi_{V}(\omega)+\Phi_{D A C}(\omega) \cdot \frac{K_{0}^{2}}{\omega^{2}}\right)
\end{aligned}
$$

위 식을 살펴보면 루프 필터의 대역 내에서의 위 상 잡음은 기준 주파수와 offset 주파수중 가장 나쁜 위상 잡음을 따라 가며 대역 외에서는 $\mathrm{VCO}(\mathrm{Voltage}$ Controlled Oscillator)와 DAC에 의한 위상 잡음 중 나 쁜 것을 따라간다는 것이다.

주목해야할 점은 빠른 위상 고정 시간 및 스위칭 속도를 갖기 위해 사용되어진 $\mathrm{DAC}$ 에 의해 더해진 노이즈 성분이 $\mathrm{VCO}$ 의 전압 이득의 제곱과 곱해진 다는 점이다. 즉, $\mathrm{DAC}$ 의 영향을 줄이려면 $\mathrm{DAC}$ 자체 의 노이즈 성분도 작아야 하지만 $\mathrm{VCO}$ 의 전압 이득 이 작을수록 주파수 합성기에 미치는 영향이 줄어든 다. 때문에 광대역의 주파수 합성기를 만들수록 $\mathrm{DAC}$ 의 영향이 커져 $\mathrm{DAC}$ 를 이용한 주파수 합성기 설계시 주의해야 한다.

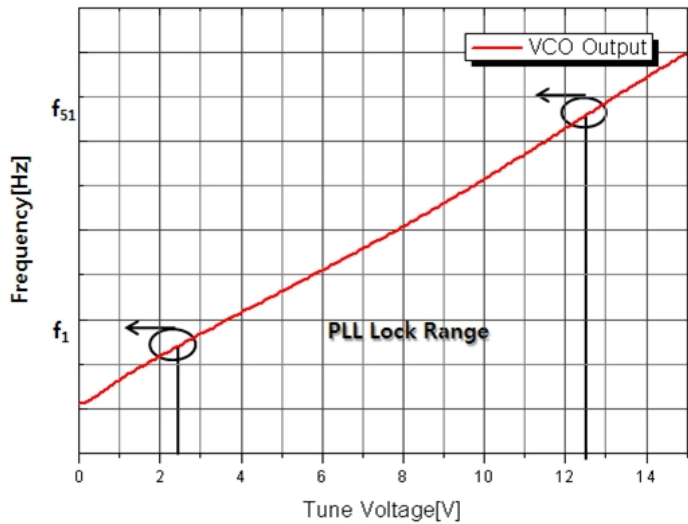

그림 4. VCO 조정 전압 vs. 출력 주파수

Fig. 4. VCO tune voltage vs. output frequency.

\section{2-4 설계 및 제작}

그림 4는 $\mathrm{DAC}$ 출력 전압 범위 확인하고자 $\mathrm{VCO}$ 의 조정 전압 대 출력 주파수를 나타낸 그래프이다. 그래프를 통해서 본 논문에서 제안한 주파수 합성기 의 출력 범위 7.XX $\sim 8 . \mathrm{XX} \mathrm{GHz}(500 \mathrm{MHz})$ 에 해당하 는 $\mathrm{VCO}$ 조정 전압은 약 $2.5 \sim 12.5 \mathrm{~V}$ 정도인 것을 확 인할 수 있었다. 설계에 쓰인 DAC는 coarse tuning전 압과 루프 필터에 의한 fine tuning 전압에 의해 고정 되는 주파수 변환 범위를 넘지 않도록 적절한 bit 제 어 가능하며 되도록 낮은 노이즈 값을 갖는 $\mathrm{A} / \mathrm{D}$ 사의 10 bit DAC(AD5433)로 선택하였다.

선택된 DAC의 output noise spectral density 값이 $25 \mathrm{nV} \sqrt{\mathrm{Hz}} @ 1 \mathrm{kHz}$ 을 갖는다.

선택된 $\mathrm{DAC}$ 의 출력이 전류로 나오기 때문에 이 를 전압으로 변환하기 위해 출력단에 연산증폭기를 이용하여 전압으로 변환하였다. 이렇게 선정된 $\mathrm{DAC}$ 에 의해 피드백 루프상에서 노이즈 영향을 살펴 보 기 위해 아래 계산식 통해 $\mathrm{VCO}$ 의 위상 잡음과 비교 하여 살펴보았다.

$$
\begin{aligned}
& S_{V C O}(\omega)=|1-H(\omega)|^{2} \cdot \Phi_{V}(\omega) \\
& S_{D A C}(\omega)=|1-H(\omega)|^{2} \cdot \frac{K_{0}^{2}}{\omega^{2}} \cdot \Phi_{D A C}(\omega)
\end{aligned}
$$

그림 5 의 계산된 결과를 보면 $\mathrm{DAC}$ 에 의한 노이 즈가 $\mathrm{VCO}$ 노이즈에 영향을 미치는 것을 확인할 수 있다. 이는 제안된 주파수 합성기가 광대역으로 설 계되어 $\mathrm{VCO}$ 의 전압 이득이 크고 $\mathrm{DAC}$ 노이즈가 


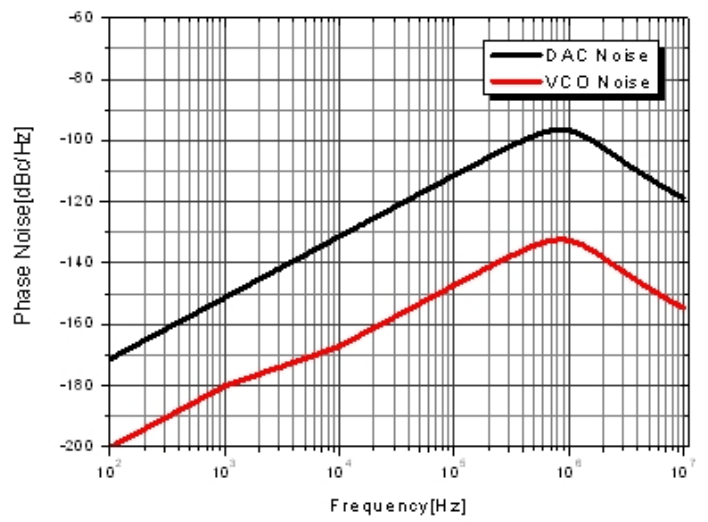

그림 5. $\mathrm{VCO}$ 와 $\mathrm{DAC}$ 노이즈 시뮬레이션 결과

Fig. 5. VCO and DAC noise simulation result.

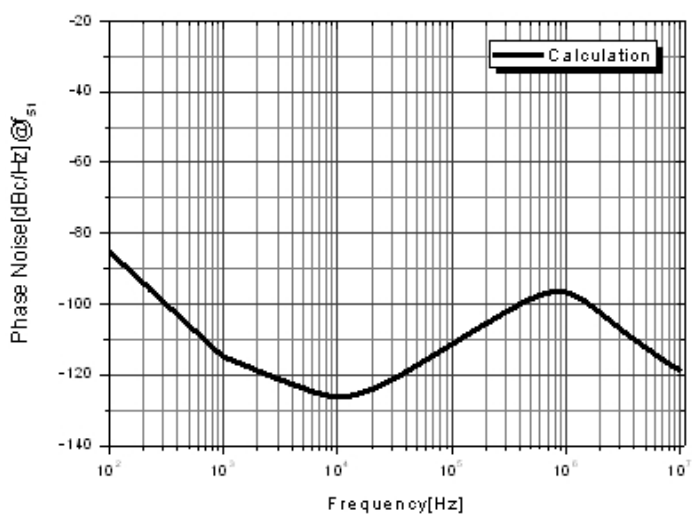

그림 6. 계산된 offset-PLL 위상 잡음

Fig. 6. Calculated offset-PLL phase noise.

$\mathrm{VCO}$ 노이즈에 영향을 미치지 않을 정도로 충분히 작지 않기 때문이라는 것을 알 수 있다.

그림 6은 제안된 offset-PLL의 최종 출력 위상 잡 음 특성을 식 (3)을 통해서 계산한 그림이다(설계된 루프 대역폭은 $1 \mathrm{MHz}$ 이다.).

그림 7은 제안된 주파수 합성기를 제작한 사진이 다. 소형화 구현을 위해 모듈의 윗면과 밑면을 사용 하여 제작되었다. 앞서 설명했듯이 윗면에는 고조파 발생기와 DDS 신호 발생부가 위치하고, 아래 면에 는 $f_{2}$ 주파수 선택을 위한 필터와 스위치가 위치한 필터뱅크와 주파수 하향 변환을 통해 비교주파수를 생성하기 위한 세 개의 믹서가 위치한다. 또한, DAC 전압조정을 위한 제어부가 위치하고 있다.

\section{$2-5$ 측정 결과}

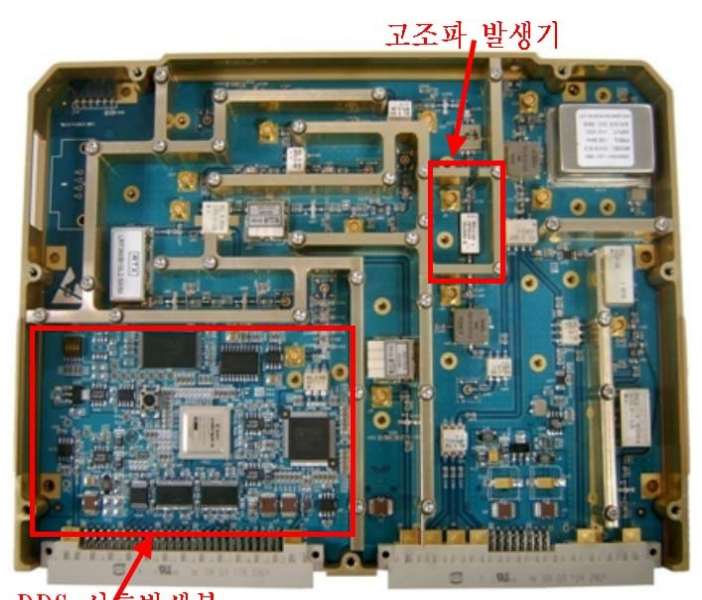

DDS 신오발생부

(a) 윗면

(a) Top view

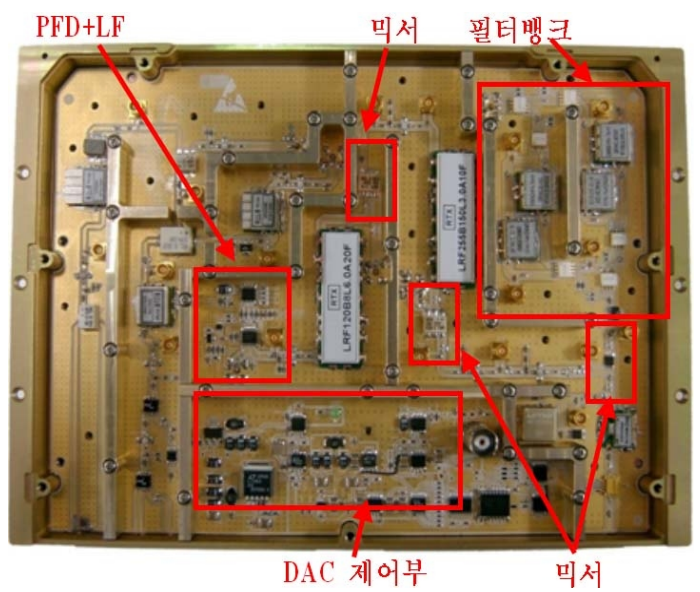

(b) 밑면

(b) Bottom view

그림 7. 제작된 주파수 합성기

Fig. 7. Manufactured frequency synthesizer.

그림 8 에서 제작된 주파수 합성기의 측정 결과와 계산된 결과를 비교한 것이다. 위상 잡음 특성이 거 의 일치하는 것을 확인할 수 있으며, 최종 출력 위상 잡음에서 주파수 합성기의 대역외 위상 잡음의 차이 는 $\mathrm{DAC}$ 데이터 시트에서 전 대역에서의 잡음 성분 을 제공하지 않아 근사화 했기 때문에 생긴 오차로 생각된다. 또한, $\mathrm{DAC}$ 에 출력 전압에 $\mathrm{DC}$ 전압 이외 의 Spur 성분의 전달을 막기 위해 단 캐패시터 성분 때문에 $\mathrm{DAC}$ 의 위상 잡음이 다소 필터링 되어 생긴 오차이다. 


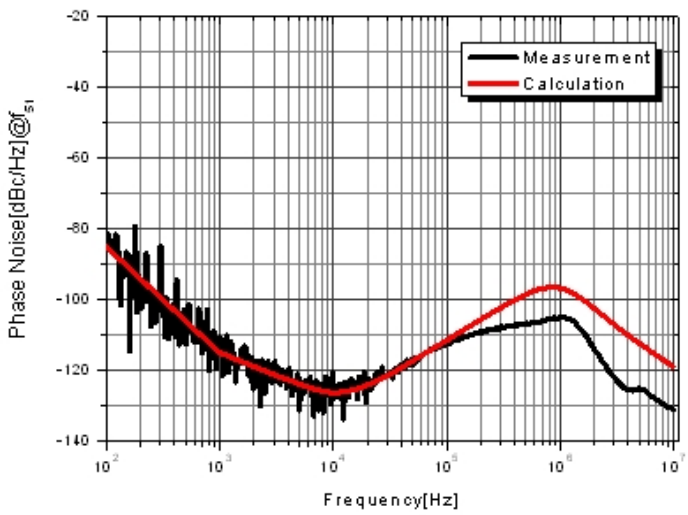

그림 8. Offset-PLL 측정 결과

Fig. 8. Offset-PLL measurement result.

\section{2-6 위상 잡음 개선}

앞서 $\mathrm{DAC}$ 에 의한 노이즈 영향에 대해서 계산 및 측정 결과를 통해 살펴보았듯이 $\mathrm{DAC}$ 노이즈가 $\mathrm{VCO}$ 의 전압 이득에 제곱하여 영향을 준다는 것을 확인 하였으며, $\mathrm{DAC}$ 에 의한 위상 잡음 열화 특성의 개선 을 시도하였다. 현재 설계 구조에서 $\mathrm{VCO}$ 의 전압 이 득은 변화시킬 수 없기 때문에 $\mathrm{DAC}$ 에서 출력되는 노이즈를 제거하여 위상 잡음을 개선하는 방법을 시 도하였다.

$\mathrm{DAC}$ 출력 노이즈를 줄이는 방법으로 그림 9 와 같이 $\mathrm{DAC}$ 에 의해 변환된 coarse tuning 전원단에 노 이즈 제거를 위한 필터를 구현하는 방법을 시도하여 개선 여부를 살펴보았다.

그림 9와 같이 $\mathrm{DAC}$ 에 의해 발생한 coarse tuning 전원 노이즈 제거를 위해 연산증폭기를 이용한 2단 필터를 설계하였으며, 설계시 주의할 점은 $\mathrm{DAC}$ 노 이즈를 많이 줄이기 위해 필터의 대역폭을 좁히게

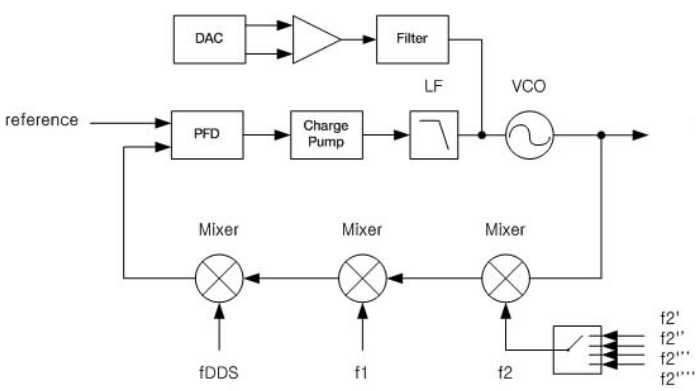

그림 9. 필터를 이용한 $\mathrm{DAC}$ 출력 노이즈 제거 Fig. 9. DAC noise cancellation using the filter.

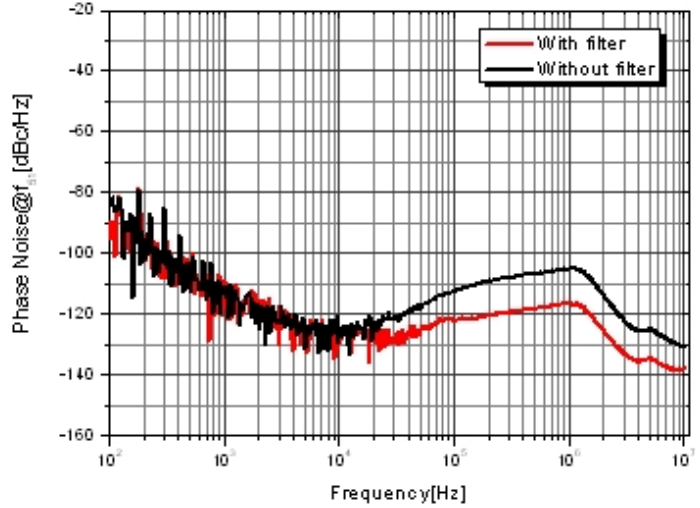

그림 10. $\mathrm{DAC}$ 출력 노이즈 제거

Fig. 10. DAC output noise cancellation.

되면 필터에 쓰이는 캐패시터 값이 커지게 되고, 그 렇게 되면 coarse tuning 전압 상승 시간이 길어지게 되어 위상 고정 시간이 늘어난다는 문제가 발생하게 된다. 따라서 위상 고정 시간에 영향을 더 미치면서 $\mathrm{DAC}$ 노이즈는 줄일 수 있는 필터의 대역폭을 적절 히 trade-off 해야만 한다. 설계된 노이즈 필터를 달아 다시 측정한 결과는 그림 10 과 같다. 측정 결과에서 도 나타났듯이 약 $10 \mathrm{~dB}$ 정도의 위상 잡음 개선 효 과가 나타남을 확인할 수 있었다. 물론 그 이상의 위 상 잡음 개선도 가능하였지만, 스위칭 시간이 늘어 나기 때문에 적정선에서 trade-off 하였다.

다음으로 제작된 주파수 합성기의 불요파 특성을 확인하고자 대역 내의 불요파 레벨을 측정하였다. 그림 11 에서 보듯이 설계 규격인 $-65 \mathrm{dBc}$ 이하보다

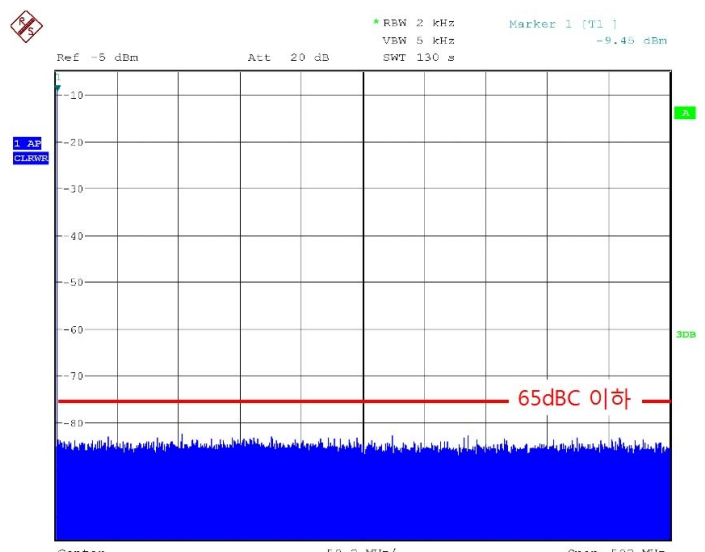

그림 11. 대역내 불요파 특성

Fig. 11. Spurious characteristic in band. 


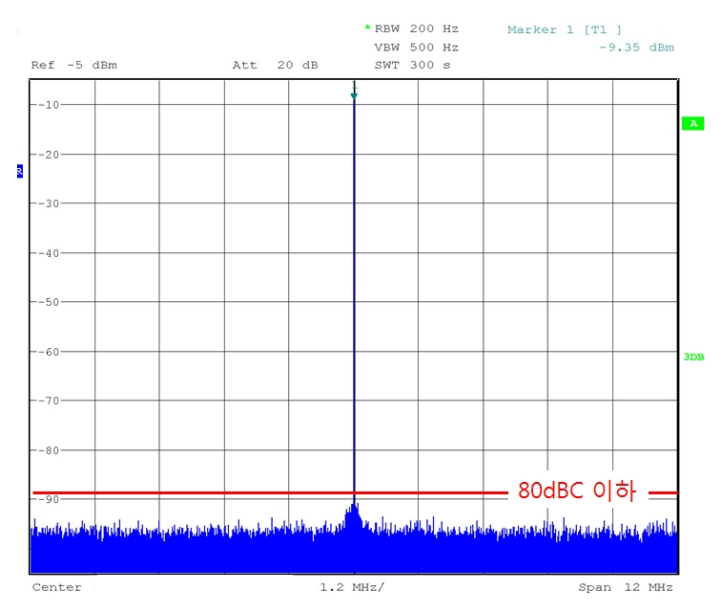

그림 12. 도플러 대역내 불요파 특성

Fig. 12. Spurious characteristic in Doppler band.

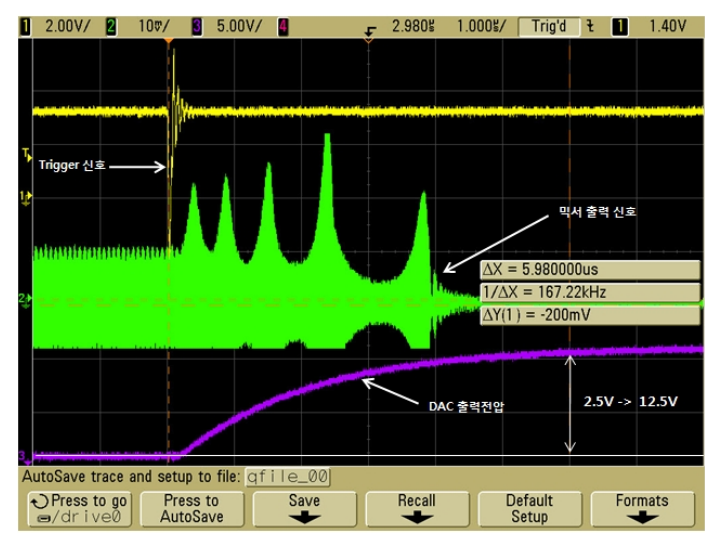

그림 13. Offset PLL의 위상 고정 시간

Fig. 13. Lock time of offset PLL.

훨씬 좋은 $-80 \mathrm{dBc}$ 이하였으며, 레이더 신호 처리 를 위한 도플러 영역 내의 불요파 특성인 규격은 그 림 12 에서 보듯이 $-90 \mathrm{dBc}$ 이하를 나타내는 것을 확 인할 수 있다.

그림 13은 제안된 offset-PLL의 스위칭 시간을 측 정한 결과로서 믹서를 이용하여 그 결과를 측정하였 다. 레이더에서는 재밍 회피를 위해 인접 주파수 변 환할 때의 위상 고정 시간뿐만 아니라 주파수 변환 시간이 가장 긴 주파수 대역의 처음 주파수에서 마 지막 주파수로 스위칭될 때의 시간도 중요하기 때문 에 인접 채널로의 위상 고정 시간보다 긴 스위칭 시 간을 측정함으로써 그 성능을 판단하였다.

그림 13 의 측정 결과에서 보는 바와 같이 주파수
표 2. Synthesizer간 성능 비교

Table 2. The comparison of the performances of synthesizers.

\begin{tabular}{|c|c|c|c|c|}
\hline \multicolumn{2}{|c|}{ 제조사 } & SATCOM & Track & 논문 \\
\hline \multicolumn{2}{|c|}{ 주파수 } & $\begin{array}{c}6.16 \sim 6.68 \\
\mathrm{GHz}\end{array}$ & $7 \sim 9 \mathrm{GHz}$ & 7. $x x \sim 8 . x x$ \\
\hline \multicolumn{2}{|c|}{ 주파수 해상도 } & $1 \mathrm{kHz}$ & $1 \mathrm{MHz}$ & $1 \mathrm{kHz}$ 이하 \\
\hline \multirow{5}{*}{$\begin{array}{l}\text { 위 } \\
\text { 상 } \\
\text { 잡 } \\
\text { 음 }\end{array}$} & $100 \mathrm{~Hz}$ & $-75 \mathrm{dBc} / \mathrm{Hz}$ & - & $-80 \mathrm{dBc} / \mathrm{Hz}$ \\
\hline & $1 \mathrm{kHz}$ & $-80 \mathrm{dBc} / \mathrm{Hz}$ & - & $-110 \mathrm{dBc} / \mathrm{Hz}$ \\
\hline & $10 \mathrm{kHz}$ & $-93 \mathrm{dBc} / \mathrm{Hz}$ & $-110 \mathrm{dBc} / \mathrm{Hz}$ & $-125 \mathrm{dBc} / \mathrm{Hz}$ \\
\hline & $100 \mathrm{kHz}$ & $-100 \mathrm{dBc} / \mathrm{Hz}$ & $-115 \mathrm{dBc} / \mathrm{Hz}$ & $-122 \mathrm{dBc} / \mathrm{Hz}$ \\
\hline & $1 \mathrm{MHz}$ & $-125 \mathrm{dBc} / \mathrm{Hz}$ & $-120 \mathrm{dBc} / \mathrm{Hz}$ & $-118 \mathrm{dBc} / \mathrm{Hz}$ \\
\hline \multicolumn{2}{|c|}{ Lock time } & - & $500 \mathrm{~ns} \max$ & $6 \mu \mathrm{s}$ 이하 \\
\hline
\end{tabular}

합성기의 주파수가 $f_{1} \rightarrow f_{51}(\mathrm{BW}=500 \mathrm{MHz})$ 로 이동시 스위칭 시간은 $6 \mu \mathrm{s}$ 이하의 스위칭 시간이 걸리는 것을 확인했으며, 이는 일반적으로 레이더에서 사용 되는 주파수 합성기의 스위칭 시간이 $10 \mu \mathrm{s}$ 이하인 점을 고려할 때 빠른 스위칭 속도라고 생각된다.

\section{III. 결 론}

본 논문에서는 기존의 offset-PLL 방식을 개선하 여 낮은 위상 잡음 특성과 높은 주파수 해상도 및 빠 른 스위칭 속도를 갖는 주파수 합성기를 설계/제작 하였다. 제안된 offset-PLL의 위상 등가 모델을 통하 여 출력 위상 잡음을 예측하였으며, 측정 결과와 비 교하여 거의 일치함을 확인할 수 있었으며, 빠른 스 위칭 속도를 위해 사용된 $\mathrm{DAC}$ 에 의해서 전체 위상 잡음이 어떻게 영향을 받는지 계산 및 확인을 할 수 있었다. 또한, $\mathrm{DAC}$ 에 의한 위상 잡음 영향을 줄이기 위해 coarse tuning 출력단에 DAC 출력 노이즈 제거 용 필터를 적용함으로써 $\mathrm{DAC}$ 에 의한 노이즈 영향 을 줄일 수 있었다.

마지막으로 제작된 주파수 합성기의 성능을 표 2 와 같이 상용 제품들과 비교하였다. 비교 규격중 스 위칭 시간은 최근 나오는 제품들이 거의 대부분 direct 방식의 주파수 합성을 하기 때문에 본 논문의 제품과 성능 비교에 어려움이 있고, 위상 잡음과 주 파수 해상도 면에서 비교하여 보면 상용 제품과 비 교하여도 상당히 우수하다는 것을 확인할 수 있다. 


\section{참 고 문 헌}

[1] F. M. Gardner, Phase Lock Techniques, Wiley, New York, pp. 104-106, 1966.

[2] U. L. Rohde, "Synthesizer design for microwave applications", Synergy Microwave Corporation, pp. 151.

[3] C. F. Lee, S. T. Peng, "Systematic analysis of the offset-PLL output spur spectrum", IEEE Tans., vol. 53, no. 9, pp. 3034-3034, 2004.

[4] J, H. Choi, M. S. Kim, S. H Shin, and Y. G. Yang, "Low phase noise S-band PLL frequency synthe-

임 주 현

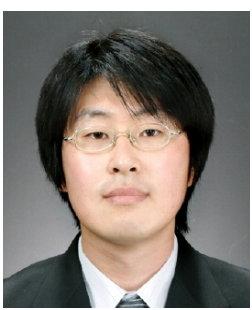

수신기
2005년 2월: 충남대학교 전기전자 전파공학과 (공학사)

2007년 2월: 충남대학교 전파공학 과 (공학석사)

2006년 12월 현재: 삼성탈레스(주) 레이더연구소 선임연구원

[주 관심분야] 레이더 시스템 및 송 sizer using DDS and offset mixing techniques", Microwave Conference, vol. 53, no. 9, pp. 1409-1412, Dec. 2009.

[5] H. G. Ryu, Y. S. Li, and J. S. Park, "Nonlinear analysis of the phase noise in the OFDM communication system", IEEE Tans., vol. 50, no. 1, pp. 5463, 2004.

[6] K. J. Song, J. I. Lee, and H. S. Shim, "Frequency synthesizer using dual offset mixing for low phase noise and narrow resolution", IEEE International Frequency Control Symposium and Exposition., vol. 53, no. 9, pp. 224-227, Jun. 2006.

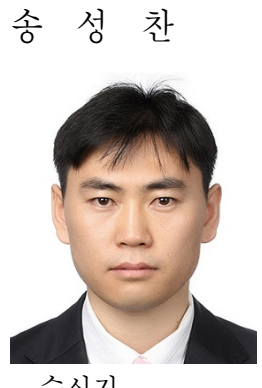

2001년 2월: 한국항공대학교 항공 전자공학과 (공학사)

2003년 2월: 한국항공대학교 항공전 자공학과 (공학석사) 2002년 11월 현재: 삼성탈레스(주) 레이더연구소 전문연구원

[주 관심분야] 레이더 시스템 및 송 수신기 